\title{
Reductions in Multi-component Jet Noise by Water Injection
}

\author{
Thomas D Norum* \\ NASA Langley Research, Hampton, VA, 23681
}

\begin{abstract}
An experimental investigation was performed in the NASA Langley Low Speed Aeroacoustics Wind Tunnel to determine the extent of jet exhaust noise reduction that can be obtained using water injection in a hot jet environment. The effects of water parameters such as mass flow rate, injection location, and spray patterns on suppression of dominant noise sources in both subsonic and supersonic jets were determined, and extrapolations to full-scale engine noise reduction were made. Water jets and sprays were injected in to the shear layers of cold and hot circular jets operating at both subsonic and supersonic exhaust conditions. Use of convergent-divergent and convergent nozzles (2.7'D) allowed for simulations of all major jet noise sources. The experimental results show that water injection clearly disrupts shock noise sources within the jet plume, with large reductions in radiated shock noise. There are smaller reductions in jet mixing noise, resulting in only a small decrease in effective perceived noise level when projections are made to full scale. The fact that the measured noise reduction in the direction upstream of the nozzle was consistently larger than in the noisier downstream direction contributed to keeping effective perceived noise reductions small. Variations in the operation of the water injection system clearly show that injection at the nozzle exit rather than further downstream is required for the largest noise reduction. Noise reduction increased with water pressure as well as with its mass flow, although the type of injector had little effect.
\end{abstract}

\section{Introduction}

Water has been used to reduce large pressure fluctuations propagating from supersonic jets. For example, large amounts of water are supplied during space shuttle launches to suppress solid rocket motor ignition overpressures in order to minimize their impact on shuttle structure ${ }^{1}$. Over the past few years, research ${ }^{2-5}$ on model scale aircraft exhaust jets has shown that various levels of noise reduction can be obtained by injecting water into these jets. The objective of the current study is to understand the effects of water injection on the noise reduction of each of the components that dominate noise generated by an exhaust jet over different ranges of operating conditions. This is accomplished by studying a jet at a condition for which the generated noise is dominated by that component.

\section{Test Facility and Hardware}

Experiments were performed in the Low Speed Aeroacoustics Wind Tunnel of the Jet Noise Laboratory at NASA Langley Research Center. The facility exhaust fan provides a free jet of ambient air exiting from a 4.7 ' by 4.7' nozzle at Mach numbers between 0.10 and 0.32 . The propulsion model is mounted at the center of the free jet and is supplied with high-pressure air that is temperature controlled by electric heaters supplemented by propane burners for elevated temperature. The wind tunnel collector and test section walls are acoustically treated to provide reflection-free measurements above $100 \mathrm{~Hz}$. Acoustic measurements are made with array of 28 quarter-inch freefield microphones located along a line parallel to the jet centerline at a distance of $11.5^{\prime}$. The microphones are aimed at the propulsion nozzle exit and provide acoustic results for angles between $45^{\circ}$ and $150^{\circ}$ to the inlet axis.

Two round propulsion nozzles were used in the current tests. The first nozzle, originally constructed for the Advanced Subsonic Transport (AST) Program, is a convergent nozzle (CON) that has a smooth internal convergence from a diameter of 5.37" to an exit diameter of 2.67" at a convergence angle of $11^{\circ}$. The other nozzle is a convergent-divergent nozzle (CD) constructed with a profile designed for shock-free flow at an exit Mach number of 1.5. It also has a throat diameter of 2.67", has an exit diameter of 2.89", and provides for parallel flow at the nozzle exit. The size of these nozzles required a scale factor of 9 (and acoustic measurements to $90 \mathrm{kHz}$ ) for acoustic

\footnotetext{
${ }^{*}$ Senior Research Engineer, Aeroacoustics Branch, MS 166, AIAA Member
} 
projections to be made to a full-scale nozzle throat diameter of 24", a size representative of CD nozzles of military fighter aircraft.

The injected water was supplied from a tank filled from the municipal water supply system and pressurized to about $160 \mathrm{psig}$. The supply piping contained a regulator and flow meter to control and measure the pressure and water flow rate. The water was piped into the test section to a ring-type manifold of 18 " diameter mounted on an axial traversing system. The manifold was constructed for water injection around the circumference of the gas jet at up to 24 equally spaced circumferential locations and at four possible angles to the jet axis. Water was injected from both circular jet injectors and commercial spray injectors, the latter described by the manufacturer as delivering $90^{\circ}$ conical sprays with medium atomization. The measured flow rate, diameter, and designation used for each injector are given in Table 1. A photograph of the test setup with 6 installed injectors is shown in Fig. 1.

Table 1 : Details of water injectors.

\begin{tabular}{|c|c|c|c|}
\hline Injector type & Injector designation & Injector diameter, in & $\begin{array}{c}\text { Single injector flow rate } \\
\text { @ 150 psig, gal/min }\end{array}$ \\
\hline jet & J1 & 0.031 & 0.19 \\
\hline jet & J2 & 0.063 & 0.89 \\
\hline jet & J3 & 0.125 & $>3.40$ \\
\hline spray & S5 & 0.043 & 0.42 \\
\hline spray & S6 & 0.055 & 0.82 \\
\hline spray & S7 & 0.072 & 1.25 \\
\hline
\end{tabular}

\section{Test Design}

The test was designed to determine the effects of water injection on each of the major jet noise sources, both hot and cold, and both subsonic and supersonic. Water injection parameters included the ratio of water to gas flow rates (mass flow ratio, MFR), type of injector (jet or spray), number of circumferential injectors $(6,12$, or 24 ), angle of injection $\left(45^{\circ}\right.$ and $60^{\circ}$ relative to the exhaust jet axis), and axial location of the injection. The wind tunnel free jet was operated at Mach 0.1, which helped to eliminate water from the test section.

The first phase of the test, conducted in late summer, consisted of acoustic testing of both propulsion nozzles (prior to installing the water injector hardware) at fully expanded Mach numbers from 0.40 to 1.55 (nozzle pressure ratios from 1.12 to 3.95 ) at total temperatures of $100^{\circ} \mathrm{F}$ (cold) and $1100^{\circ} \mathrm{F}$ (hot). Acoustic spectra from the $45^{\circ}$ microphone established the minimum shock noise condition of the CD nozzle $\left(\mathrm{M}_{\mathrm{j}}=1.48\right.$ cold and 1.45 hot $)$. Noise measurements also established for the CD nozzle's over-expanded jets the conditions of maximum broadband shock noise in the absence of screech domination $\left(\mathrm{M}_{\mathrm{j}}=1.15\right.$ cold and 1.30 hot $)$, and for the convergent nozzle's under-expanded jets the maximum screech condition $\left(\mathrm{M}_{\mathrm{j}}=1.30\right)$. A list of the jet noise sources and best condition for their domination are given in Table 2.

Table 2 : The nozzle and flow condition that best produces the desired dominant noise sources

\begin{tabular}{|l|c|c|c|}
\hline Dominant Jet Noise Source & Nozzle & NPR & $\mathbf{M}_{\mathbf{j}}$ \\
\hline Hot subsonic jet mixing noise (not obtained) & CON & 1.52 & 0.80 \\
\hline Cold subsonic jet mixing noise & CON & 1.52 & 0.80 \\
\hline Cold over-expanded subsonic jet noise & CD & 1.52 & 0.80 \\
\hline Hot over-expanded subsonic jet noise & CD & 1.52 & 0.80 \\
\hline Cold over-expanded supersonic jet broadband shock noise & CD & 2.27 & 1.15 \\
\hline Hot over-expanded supersonic jet broadband shock noise & CD & 2.77 & 1.30 \\
\hline Cold under-expanded supersonic jet screech & CON & 2.77 & 1.30 \\
\hline Hot supersonic jet mixing noise / Mach wave radiation & CD & 3.42 & 1.45 \\
\hline Cold supersonic jet mixing noise (contaminated) & CD & 3.57 & 1.48 \\
\hline
\end{tabular}

The water injection hardware was installed for the second phase of the test. This phase was conducted in late fall through mid-winter. A typical sequence of noise reduction results at a given gas flow condition was obtained from an acoustic measurement without water flow, followed by three succeeding measurements with water injected at 
different flow rates, followed by a fifth measurement with the water turned off. Most of the testing required use of the CD nozzle and was performed first. Unfortunately, the water-cooling system required for high temperature flow failed prior to installation of the convergent nozzle, so water injection results for this nozzle were obtained for cold flow only.

For the third phase the test section was reconfigured to its usual anechoic state by removing the water injection hardware and acoustic measurements were again taken for the cold conditions. These measurements were performed with both propulsion nozzles and occurred in late winter.

\section{Results}

The results for the reductions in jet noise with water injection are separated into subsections, each dealing with one of the dominant noises listed in Table 2. Noise comparison plots shown for the most successful injector configuration give narrow band sound pressure level (SPL) spectra with and without water injection at angles of $45^{\circ}$, $90^{\circ}$, and $135^{\circ}$, along with the sideline directivity of overall sound pressure level (OASPL). Full scale projection plots show noy spectra at these same angles along with the perceived noise level (PNL) directivity, from which the effective perceived noise level (EPNL) of an aircraft flyover is calculated. (No tone corrections were applied in the EPNL computations). Also shown are selected plots giving the effects of changing the injector parameters on the OASPL reduction, which is defined as the maximum reduction in OASPL of the 28 microphones (usually found to occur at the $45^{\circ}$ microphone). On these plots injector configurations are indicated as S5/12/60, which means injector type S5, number of circumferential injectors equal to 12 , and angle of injection of $60^{\circ}$ (where $90^{\circ}$ is perpendicular to the jet axis).

\section{A. Cold Subsonic Jet Mixing Noise}

The jet used to investigate cold subsonic mixing noise issued from the convergent nozzle at a Mach number of 0.8 and a stagnation temperature of $100^{\circ} \mathrm{F}$. At this jet condition, the OASPL reductions with water injection vs. mass flow ratio at five injector configurations are shown in Fig 2. The noise reduction increases with increasing water flow, with little difference between configurations at the same water flow rate. The very small differences in noise reductions between jet and spray injectors were in accordance with the visual observation that the columns of water from jet injection were dispersed immediately upon impinging the propulsion jet, indicating an atomization process similar to that produced mechanically by the spray injectors. The maximum OASPL reduction shown in Fig. 2 was $3.7 \mathrm{~dB}$, occurring at the highest mass flow ratio used (MFR $=0.56$ ). The measured noise spectra with and without water injection are shown in Fig. 3. The spectra show that the reduction occurs over a wide frequency range, and the sideline directivity shows the OASPL reduction is roughly the same at most angles. The corresponding full scale noy spectra are given in Fig. 4. The large differences in the noy values at the high-weighted frequencies (centered at $2 \mathrm{kHz}$ ), yield correspondingly high differences in the PNL directivity, resulting in an EPNL difference of $2.7 \mathrm{~dB}$. (Note that although the flyover Mach number was chosen as 0.1 for the EPNL calculation, the same difference in EPNL is obtained for these noise measurements for any assumed aircraft velocity).

\section{B. Cold Over-expanded Subsonic Jet Noise}

The jet for this case has the same stagnation conditions as the previous one (NPR $=1.52$ and $\left.\mathrm{T}_{\mathrm{j}}=100^{\circ} \mathrm{F}\right)$, but exhausts from the Mach 1.5 CD nozzle rather than from the convergent nozzle. As the NPR is increased above choking for this nozzle, a normal shock moves down the divergent section of the nozzle and reaches the exit plane just prior to NPR $=1.52$. The jet quickly compresses to the ambient pressure upon leaving the nozzle. As will be shown below, the noise reduction from water injection of this jet is very similar to that of the convergent nozzle, so results at the corresponding hot condition can be used to estimate the effects of water injection on hot subsonic mixing noise, in lieu of the lack of hot testing with the convergent nozzle.

The maximum OASPL reduction for this case was obtained with the same injector configuration, J2/12/60, as was obtained with the convergent nozzle. The measured spectra with and without water injection are given in Fig. 5. A comparison with Fig. 3 shows that the spectra from the two nozzles without water flow differ at the higher frequencies, which results in an OASPL level for the CD nozzle about $2 \mathrm{~dB}$ higher than the convergent nozzle over the mid-angle measurement range. The higher noise level of the CD nozzle can be attributed to compression of the jet caused by the over-expanded exit condition. However, the reduction in spectra and OASPL directivities (and hence also that for PNL) due to water injection are very similar for the two nozzles. The maximum OASPL and fullscale EPNL reductions obtained for the CD nozzle data in Fig. 5 were $4.0 \mathrm{~dB}$ and $2.9 \mathrm{~dB}$, very close to the values obtained with the convergent nozzle. 


\section{Hot Subsonic Over-expanded Jet Noise}

For this case the jet pressure characteristics are similar to the previous one, but jet velocity is increased and its density decreased due to the increase in jet stagnation temperature to $1100^{\circ} \mathrm{F}$. This reduces the gas flow rate considerably, resulting in a higher mass flow ratio for a given amount of injected water.

For this hot jet, configuration J2/12/45 gave large noise reductions due to water injection. The spectra shown in Fig. 6 show the lower frequencies to be reduced most, and the OASPL reduction to be much larger in the upstream direction than near the peak noise angles. These observations carry over to the projected full-scale PNL shown in Fig. 7. Because the hot jet has much steeper noise directivity than the cold jet, and the noise reductions are lowest near the peak noise angles, the EPNL reduction is more disappointing. The maximum OASPL reduction of $5.1 \mathrm{~dB}$ translates into only a $1.6 \mathrm{~dB}$ reduction in full scale EPNL.

\section{Cold Over-expanded Supersonic Jet Broadband Shock Noise}

As the Mach 1.5 CD nozzle increases in NPR, numerous shock cells form in the jet plume. Interaction of the jet turbulence with the shocks produces a broadband shock noise component that can dominate the noise spectra in the forward arc at all but low frequencies. Oscillation of the shocks can result in additional noise, called jet screech, with the spectra dominated by screech tones. For cold operation of the Mach 1.5 CD nozzle, the highest NPR that can be obtained prior to the onset of dominant screech is about 2.27, corresponding to $\mathrm{M}_{\mathrm{j}}=1.15$, at which cold overexpanded supersonic broadband shock noise was investigated.

The maximum OASPL noise reduction due to water injection for this noise component was $13.7 \mathrm{~dB}$ at the furthest upstream microphone, again from injector configuration J2/12/45. The spectral data for this configuration is given in Fig. 8. The broadband shock noise hump, peaking at about $5 \mathrm{kHz}$ at the $45^{\circ}$ microphone, is seen to be almost eliminated by the injected water. Noise reductions are largest in the shock noise dominated forward directions, but occur at all angles, with low frequencies usually associated with jet mixing noise being reduced much less that the broadband shock noise. In that the shock noise humps in the spectra are due to favorable phase relationship of the noise generated at the successive shock cells, the implication is that the primary effect of the water is to disrupt this relationship.

The noy reductions shown in Fig. 9 are equally impressive as those of the SPL, with the peak noy reductions occurring at the highly weighted portion of the full-scale projections (about $2 \mathrm{kHz}$ ), leading to an EPNL decrease of a hefty $8.2 \mathrm{~dB}$.

The large noise reductions obtained for this case allowed for an investigation of the various water injection parameters. Figure 10 through 12 give broadband shock noise OASPL reduction vs. mass flow ratio. In Fig. 10, both injector type and injection angle are varied. A comparison of the two sets of jet injector $\mathrm{J} 2$ data (and also the two spray injector S5 sets) shows that injection at $60^{\circ}$ yields a somewhat higher noise reduction than $45^{\circ}$. Also, comparing data for the two types of injectors at a given injector angle indicates jet and spray injectors are equally effective at a given mass flow ratio.

In Fig. 11 the axial injection location is varied for the given injector configuration J2/12/60. The injector ring was moved to injection locations corresponding to known ${ }^{6}$ positions of the shocks in the jet plume. The figure shows that injection at the nozzle exit gives the largest noise reduction, and that the reduction gets smaller as the injection location is moved downstream, all but disappearing when injection occurs beyond the $5^{\text {th }}$ shock cell.

Figure 12 gives the noise reduction obtained as the number of circumferential injectors is changed. The data show that at a given water injection rate, the fewest number of injectors yields the largest noise reduction. This apparent inconsistency is clarified in Fig. 13, in which the same noise reductions are given vs. the water supply pressure. This figure shows that at the same injection pressure, the better circumferential coverage of the higher number of injectors does give the larger noise reduction. As the number of injectors decrease, a higher pressure (and hence higher injection velocity) is required to provide the same water flow rate. Hence, the data in Figs. 12 and 13 indicate that water pressure is as important a parameter as its flow rate for providing maximum noise reduction.

\section{E. Hot Over-expanded Supersonic Jet Broadband Shock Noise}

Because screech did not dominate the CD nozzle at any over-expanded NPR at $1100^{\circ} \mathrm{F}$, the investigation of hot broadband shock noise was able to be performed at $\mathrm{Mj}=1.30$, the condition corresponding to the occurrence of the maximum over-expanded shock noise levels. Spectra with and without water injection are given in Fig.14 using the same injector configuration as for the cold shock noise case of Fig. 8. The maximum OASPL reduction, occurring at the $45^{\circ}$ microphone, is $6.6 \mathrm{~dB}$ (the larger jet injector $\mathrm{J} 3$ got only about an additional $0.5 \mathrm{~dB}$, at about twice the water flow rate). As with the comparison of the hot and cold subsonic cases, higher noise levels in the downstream direction combined with smaller water-induced noise reductions in the forward direction lead to a much lower 
EPNL reduction at the hot condition. The full-scale projections of Fig. 15 show the noy values in the downstream direction dominate the EPNL reduction due to water injection, which amounts to only $1.3 \mathrm{~dB}$.

The large differences between noise directivities of hot and cold cases of over-expanded supersonic jet broadband shock noise are caused by differences in the mix of dominant noise sources. Because broadband shock noise is basically pressure dependent, there is very little change in the observed broadband shock noise levels as temperature is increased at a given NPR. On the other hand, jet mixing noise and Mach wave radiation are mainly velocity dependent, so that their level increases sharply as the temperature increases. These facts can be seen from a comparison of spectral levels of cold and hot jets (without water injection) in Figs. 8 and 14. The difference in the peaks of the shock noise at the $45^{\circ}$ microphone is about $10 \mathrm{~dB}$, due to the increase in $\mathrm{M}_{\mathrm{j}}$ from 1.15 to 1.30 . This is caused by an increase in jet stagnation pressure that results in stronger shocks in the jet plume. However, the peak in the spectra at $135^{\circ}$, which is dominated by Mach wave radiation, is over $20 \mathrm{~dB}$ higher for the hot jet. This is due to the large increase in jet velocity that is caused somewhat by the increase in pressure, but primarily by the increase in temperature.

The reduction in noise due to water injection is seen to be much larger for broadband shock noise than for jet mixing noise. When the jet temperature is increased at a given NPR, the ratio of shock noise to mixing noise decreases in the forward direction and the OASPL directivity shifts more to the Mach-wave-radiation dominated downstream direction. The combination of these two factors results in the small EPNL reduction due to water injection for the hot jet relative to the cold jet.

\section{F. Cold Under-expanded Supersonic Jet Screech}

The maximum effects of screech on spectra at the cold condition of the convergent nozzle occur near a fully expanded Mach number of 1.3. Spectra for injector configuration J2/12/60 with and without water injection are given in Fig. 16 for this condition and show that injection can not only reduce screech levels below the broadband noise levels, it can also reduce the broadband levels across the entire spectrum. The directivities show the maximum OASPL reduction, equal to $17.5 \mathrm{~dB}$, occurs at the $90^{\circ}$ microphone, which is the location of the maximum SPL level of the second harmonic of screech. The (non-tone-corrected) EPNL difference is $10.9 \mathrm{~dB}$. The mass flow ratio was 0.28 .

Spectra for injection at the lower mass flow ratio of 0.10 are shown in Fig. 17 along with spectra for configuration $\mathrm{S} 5 / 12 / 60$ at the same water rate. Note that screech tones have again been eliminated from the spectra, but the broadband noise shows a much smaller reduction than at the higher flow rate shown in Fig. 16. Also, the spectra for the jet and spray injectors are virtually identical, again indicating that both types of injection give the same noise reduction at the same water flow rate.

Noise reduction data presented for this case of cold under-expanded jet screech tones were taken with the traverse positioned for injection at an axial location equal to 0.6 nozzle diameter, which is just upstream of the first shock in the plume of this jet. This injection location gave noise reductions between 1 and $2 \mathrm{~dB}$ greater than did injection at the nozzle exit. It was the only noise component for which injection at the nozzle exit did not give the greatest reduction. However, just as for the broadband shock noise case shown in Fig. 11, the maximum OASPL reduction decreased dramatically for injection further downstream, reducing to less than $3 \mathrm{~dB}$ for injection between the $3^{\text {rd }}$ and $4^{\text {th }}$ shock cell.

\section{G. Hot supersonic jet mixing noise / Mach wave radiation}

The condition for the $\mathrm{CD}$ nozzle operating at a temperature of $1100^{\circ} \mathrm{F}$ that produced the minimum noise in the upstream direction, and hence the minimum shock noise, occurred at $\mathrm{M}_{\mathrm{j}}=1.45$. At this condition upstream noise radiation is dominated by supersonic jet mixing noise and downstream noise by Mach wave radiation. The maximum noise reductions obtained with water injection for all injectors (J2, J3, S5, and S7) that were tested at this condition are shown in Fig. 18. As for the other noise components, the noise reduction increases with increasing mass flow ratio. The spectra and directivity at the configuration of largest OASPL reduction are given in Fig. 19. The reduction is more or less evenly distributed across frequency, with the maximum of $3.8 \mathrm{~dB}$ occurring in the upstream direction. Because the noise is directed mostly in the lesser-affected downstream direction, only $0.9 \mathrm{~dB}$ EPNL reduction is obtained.

\section{H. Cold supersonic jet mixing noise}

For the cold jet $\left(100^{\circ} \mathrm{F}\right)$, the "design condition" of the CD nozzle was found to occur at $\mathrm{M}_{\mathrm{j}}=1.48$, as deduced from the upstream noise minimum obtained during the pretest. At this condition the maximum OASPL reduction from water injection was $5.9 \mathrm{~dB}$, obtained with injector configuration $\mathrm{S} 5 / 24 / 60$. Spectra for this case are given in 
Fig. 20, which yield a full-scale EPNL noise reduction of $2.2 \mathrm{~dB}$. Note that this figure is very similar to Fig. 8 , the case of cold over-expanded broadband shock noise. Hence it looks like broadband shock noise dominates the portion of the MFR $=0$ spectra in Fig. 20 that is reduced by the injected water.

Apparent shock noise in the spectra of Fig.20 is investigated in Fig.21 by comparing these spectra, labeled (a), with those obtained during the posttest and pretest, labeled (b) and (c) respectively. Note that the water injection hardware was not installed in the facility during the pretest or posttest. The differences in the SPL between (a) and (b) spectra indicate that the presence of water injection hardware apparently caused an increase in noise levels over a wide range of frequencies. However, (b) and (c) spectra show a very similar difference. Although both the pretest and posttest showed the minimum noise level in the forward direction occurred at this NPR, the spectra in Fig. 21 show significant SPL differences for all frequencies and angles. These differences, found to exist at all NPR, may be due to changes in test section ambient temperature, this temperature being (a) $34^{\circ} \mathrm{F}$, (b) $51^{\circ} \mathrm{F}$, and (c) $89^{\circ} \mathrm{F}$ for the three sets of data. The OASPL increases from the pretest to posttest to water injection test correspond to decreases in the ambient temperature. This phenomenon was also found during separate flow nozzle tests in the GEAC Free-Jet Facility ${ }^{7}$.

So, although the reason is uncertain why the spectra in Fig. 20are different from the pretest spectra, it does look as if the reduction of cold supersonic jet mixing noise that is specified above is actually due to a reduction in broadband shock noise.

\section{Conclusions}

Tests were performed to investigate the effects of water injected into jet shear layers on the different components of noise emitted by both low and high temperature round exhaust jets. In general, the amount of noise reduction obtained increased with both mass flow and pressure of the injected water, and were largest in the upstream direction.. No appreciable differences were found between jet and spray type water injectors, agreeing with the observation that injected jets were dispersed into sprays upon contact with the shear layer of the exhaust jet. Except for screech tones, injection at the nozzle exit led to the largest measured noise reductions.

Table 3 summarizes both maximum OASPL and projected full-scale EPNL reductions for each of the noise components. Both broadband and screech components of shock noise show much larger noise reductions than mixing noise for cold jets. Because shock noise becomes less significant relative to mixing noise as the jet temperature increases, reductions in OASPL are smaller for hot jets than for cold jets. Additionally, the stronger noise directivity in the downstream direction at higher jet temperatures makes reductions in EPNL very small for a hot jet.

Table 3 Maximum noise reductions by water injection of jet noise components.

\begin{tabular}{|c|c|c|c|c|c|c|}
\hline $\begin{array}{c}\text { Dominant noise } \\
\text { source }\end{array}$ & $\begin{array}{c}\text { cold jet } \\
\text { OOASPL, dB }\end{array}$ & $\begin{array}{c}\text { hot jet } \\
\text { OASPL, dB }\end{array}$ & $\begin{array}{c}\text { cold jet } \\
\Delta \text { EPNL, dB }\end{array}$ & $\begin{array}{c}\text { hot jet } \\
\Delta \text { EPNL, dB }\end{array}$ & $\begin{array}{c}\text { cold jet } \\
\text { MFR }\end{array}$ & $\begin{array}{c}\text { hot jet } \\
\text { MFR }\end{array}$ \\
\hline $\begin{array}{c}\text { subsonic jet } \\
\text { mixing noise }\end{array}$ & 3.7 & & 2.7 & & 0.56 & \\
\hline $\begin{array}{c}\text { over-expanded } \\
\text { subsonic jet noise }\end{array}$ & 4.0 & 5.1 & 2.9 & 1.6 & 0.51 & 0.84 \\
\hline $\begin{array}{c}\text { over-expanded } \\
\text { broadband shock } \\
\text { noise }\end{array}$ & 13.7 & 6.6 & 8.2 & 1.3 & 0.33 & 0.46 \\
\hline $\begin{array}{c}\text { under-expanded } \\
\text { jet screech }\end{array}$ & 17.5 & 3.4 & $2.2^{*}$ & 0.9 & 0.19 & 0.85 \\
\hline $\begin{array}{c}\text { supersonic jet } \\
\text { mixing noise / } \\
\text { Mach wave } \\
\text { radiation }\end{array}$ & $5.9^{*}$ & & & & & \\
\hline
\end{tabular}

* contaminated by broadband shock noise reduction 


\section{References}

${ }^{1}$ Ikawa, H., and Laspesa, F. S., "Analytical Understanding of WTR Ignition/Duct Overpressure Induced by Space Shuttle Solid Rocket Motor Ignition Transient,” AIAA paper 83-1113, June 1983

${ }^{2}$ Zoppellari, E., and Juve, D., "Reduction of Jet Noise by Water Injection," AIAA paper 97-1622, May 1997.

${ }^{3}$ Zoppellari, E., and Juve, D., "Reduction of Hot Jet Noise by Water Injection," AIAA paper 98-2204, June 1998.

${ }^{4}$ Washington, D., and Krothapalli, A., "The Role of Water Injection on the Mixing Noise Supersonic Jet," AIAA paper 982205, June 1998.

${ }^{5}$ Krothapalli, A., Venkatakrishnan, L., Elavarasan, R., and Lourenco, L., "Supersonic Jet Noise Suppression by Water Injection", AIAA paper 2000-2025, June 2000.

${ }^{6}$ Norum, T. D., and Seiner, J. M., "Measurements of Mean Static Pressure and Far-Fiend Acoustics of Shock-Containing Supersonic Jets," NASA TM 84521, Sep. 1982.

${ }^{7}$ Janardan, B. A., Hoff, G. E., Barter, J. W., Martens, S, and Gliebe, P. R., "AST Critical Propulsion and Noise Reduction Technologies for Future Commercial Subsonic Engines, Separate-Flow Exhaust System Noise Reduction Concept Evaluation," NASA CR-2000-210039, Dec. 2000. 


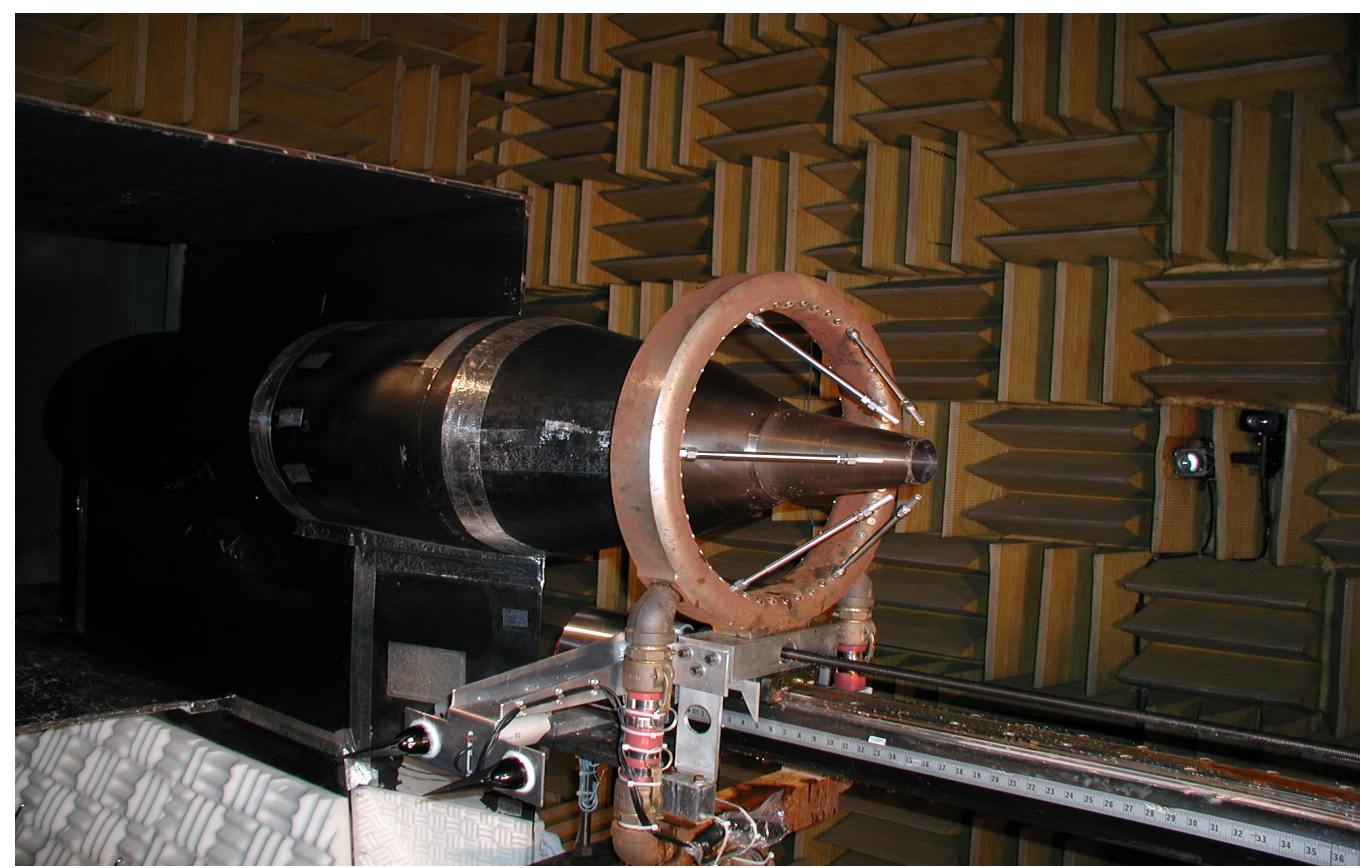

Figure 1 Water injection hardware with 6 injectors positioned for injection at nozzle exit.

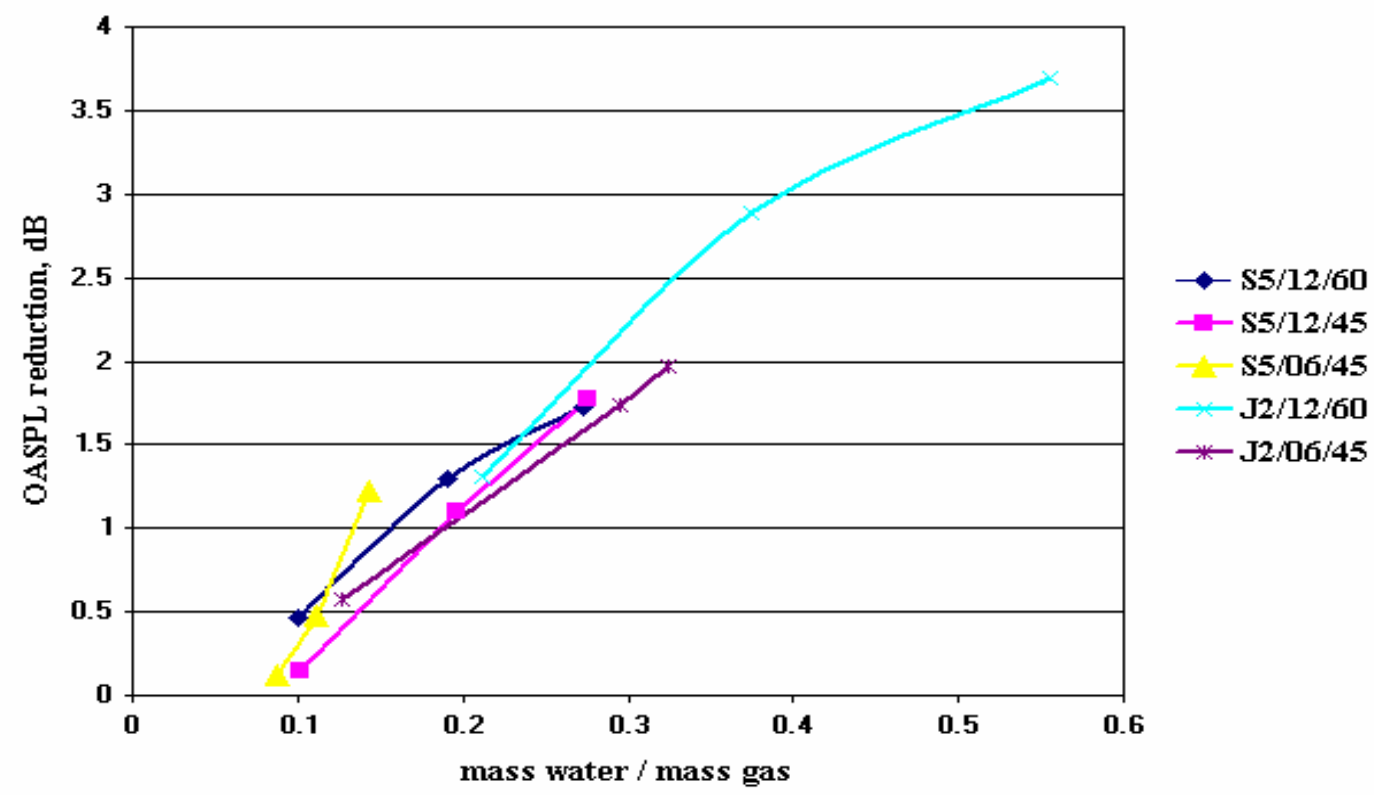

Figure 2 Maximum reductions in OASPL vs. mass flow ratio of cold subsonic jet mixing noise at different injector configurations. 

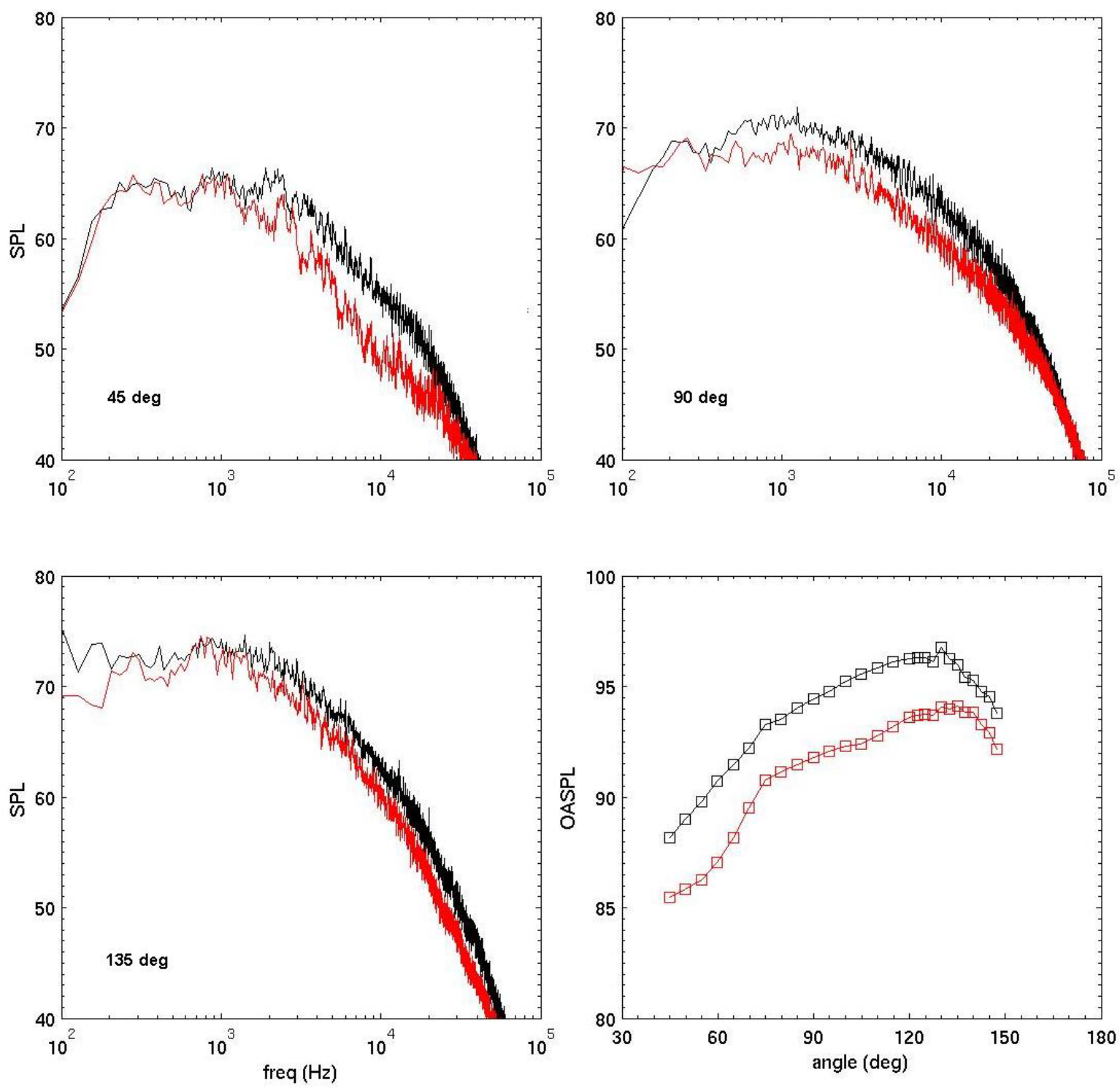

Figure 3 Spectra and directivity of cold subsonic jet mixing noise, configuration J2/12/45.

MFR $=0$ - black, MFR $=0.46$ - red. 

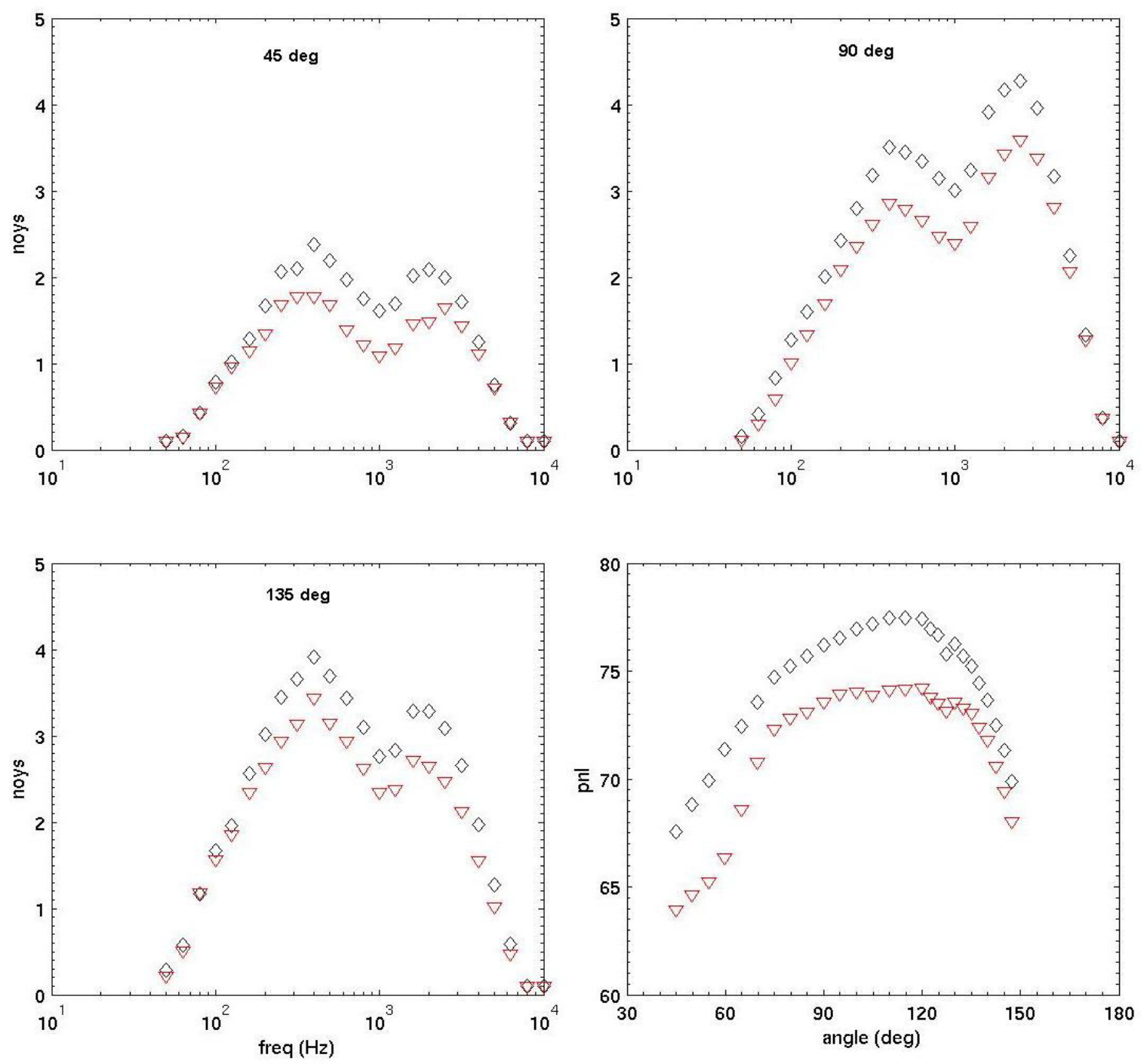

Figure 4 Full-scale noy spectra and PNL directivity of cold subsonic jet mixing noise.

MFR $=0$ - black, MFR $=0.46-\operatorname{red}, \triangle E P N L=2.7 \mathrm{~dB}$. 

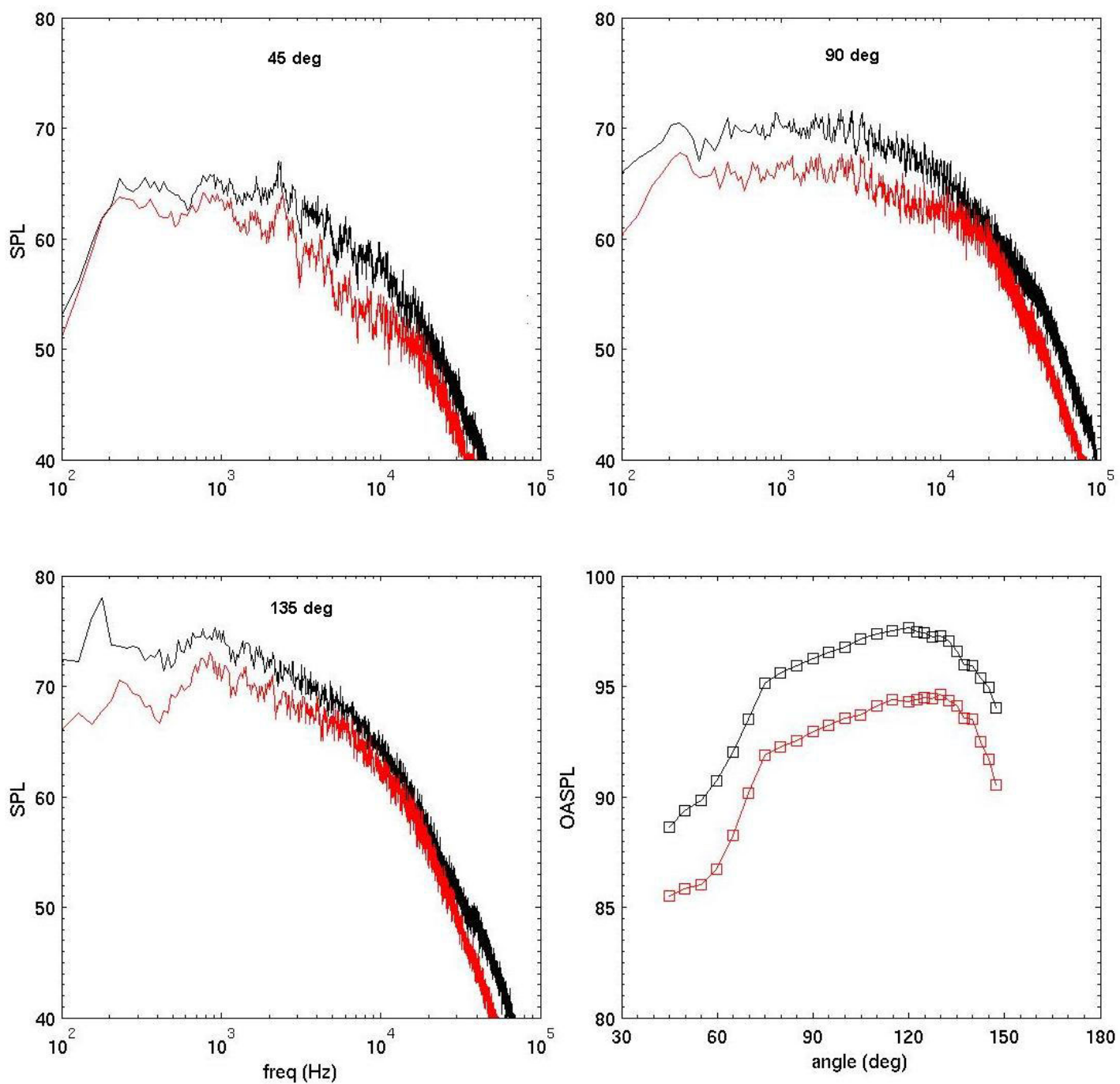

Figure 5 Spectra and directivity of cold over-expanded subsonic jet noise, configuration J2/12/60. MFR $=0$ - black, MFR = $0.46-$ red. 

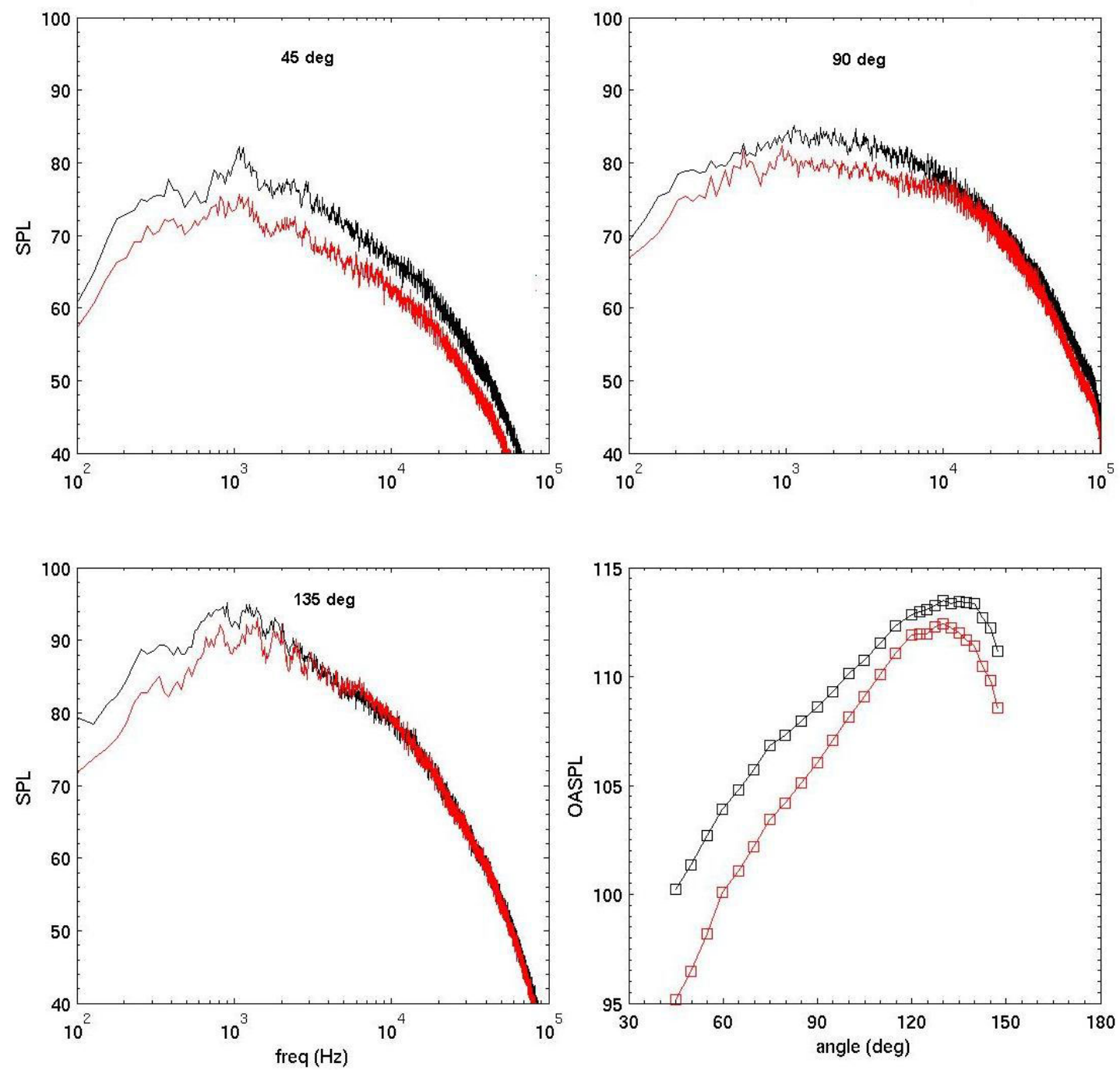

Figure 6 Spectra and directivity of hot over-expanded subsonic jet noise, configuration J2/12/45. MFR = 0 - black, MFR = $0.84-$ red. 

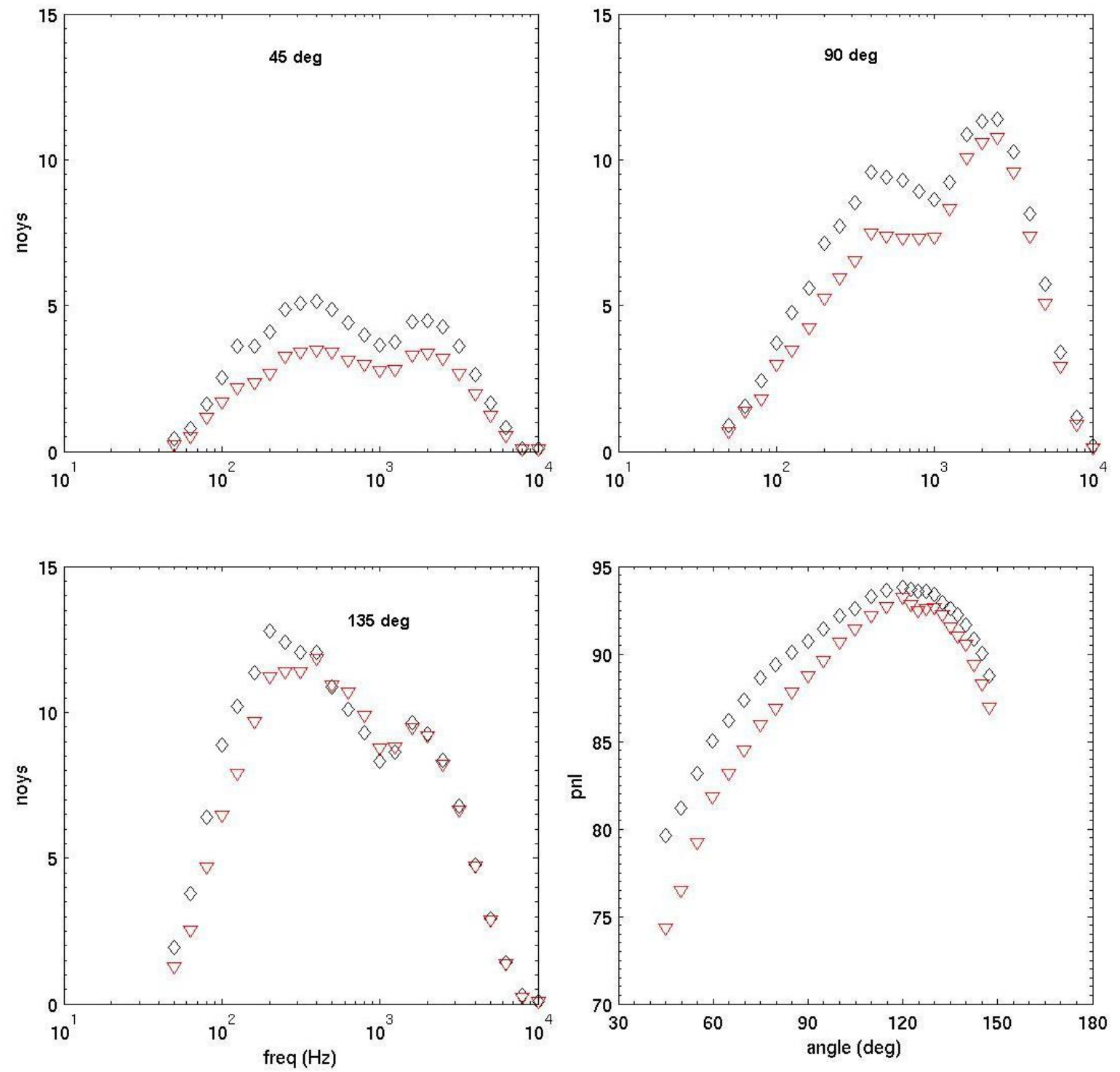

Figure 7 Full-scale noy spectra and PNL directivity of hot over-expanded subsonic jet noise. MFR $=0$ - black, MFR $=0.84-$ red, $\triangle \mathrm{EPNL}=1.6 \mathrm{~dB}$. 

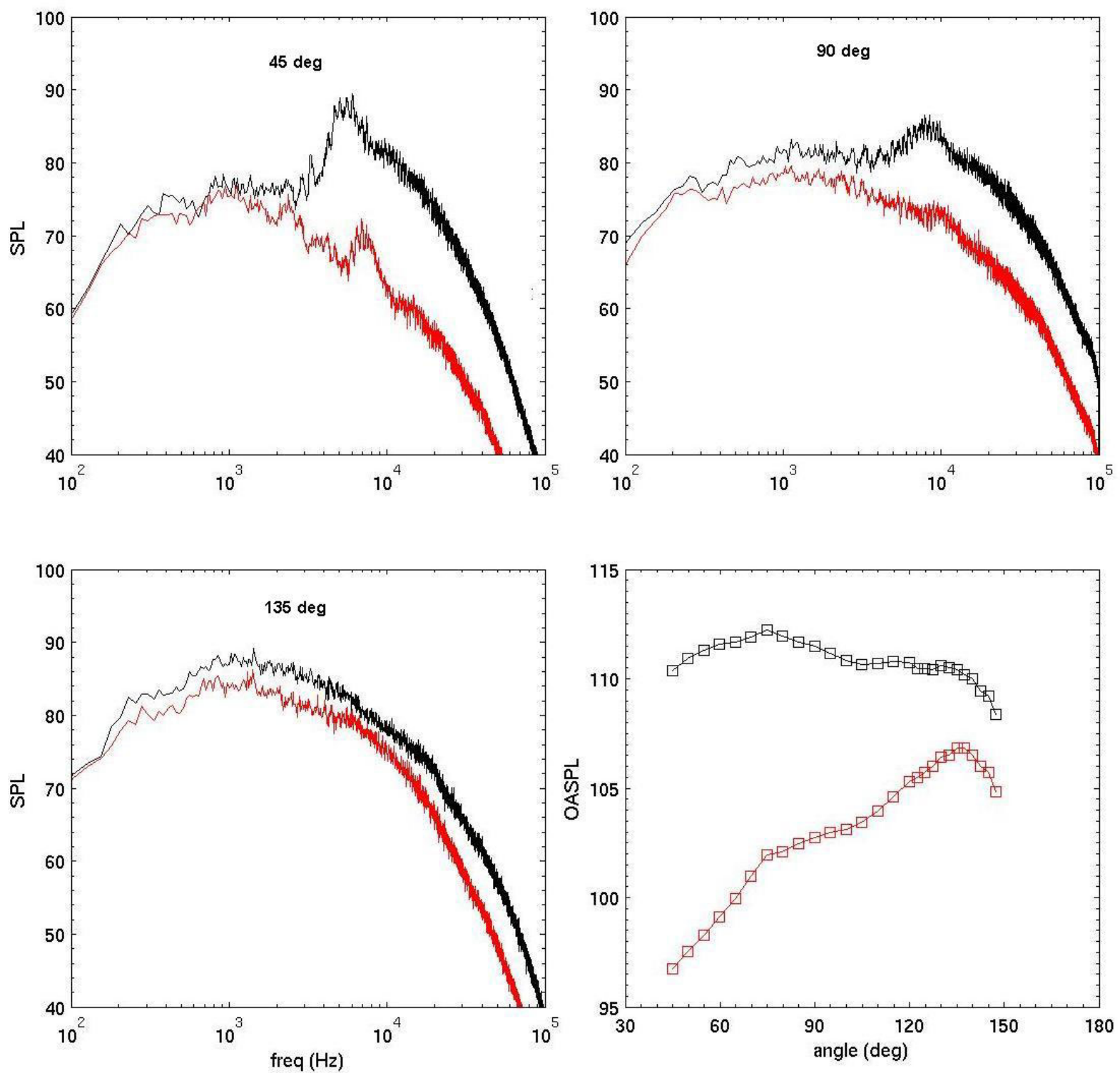

Figure 8 Spectra and directivity of cold over-expanded supersonic jet broadband shock noise, configuration J2/12/60. MFR $=0$ - black, MFR $=0.33-$ red. 

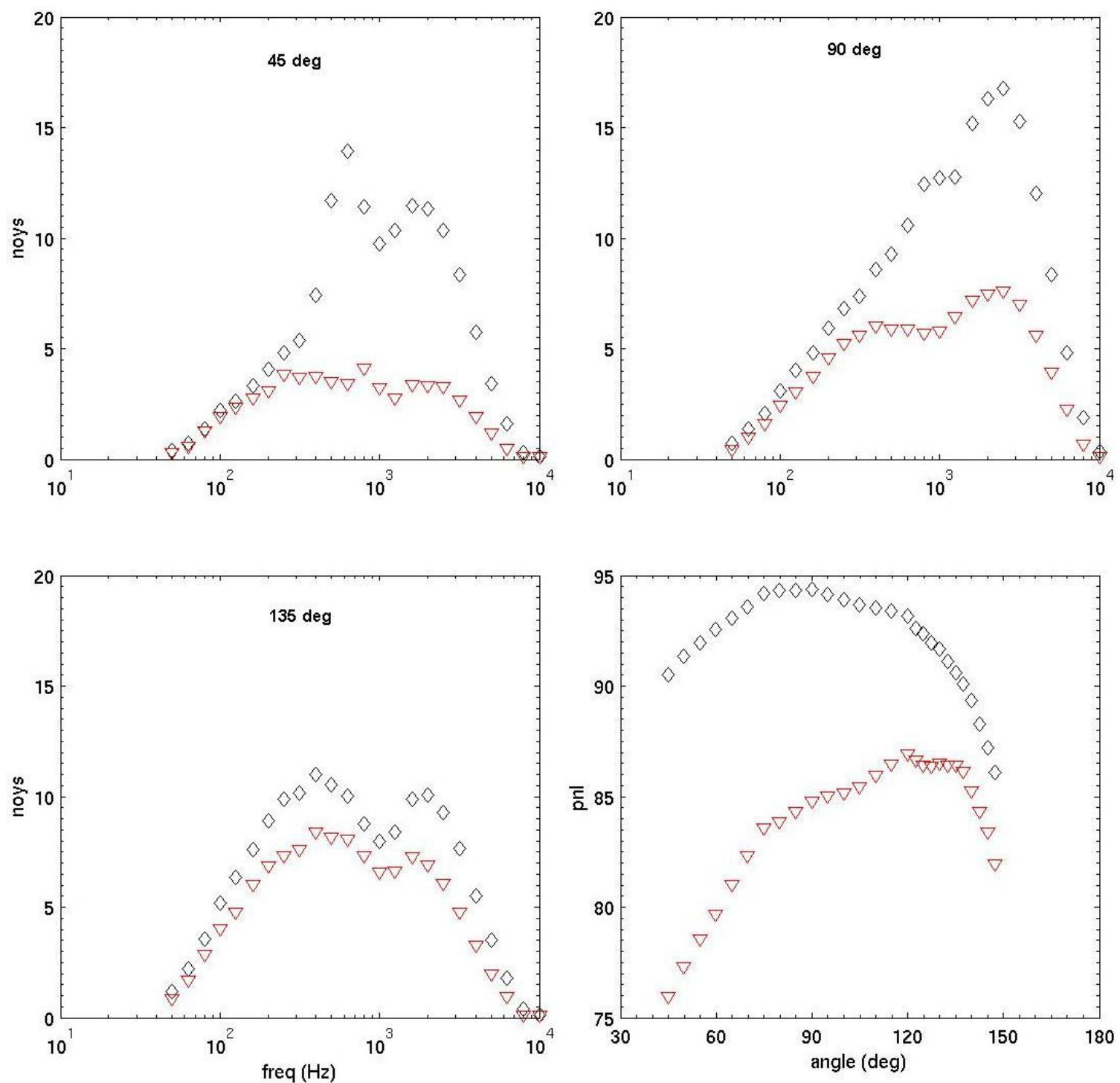

Figure 9 Full-scale noy spectra and PNL directivity of cold over-expanded supersonic jet broadband shock noise. $\mathrm{MFR}=0$ - black, $\mathrm{MFR}=0.33-$ red, $\triangle \mathrm{EPNL}=8.2 \mathrm{~dB}$. 


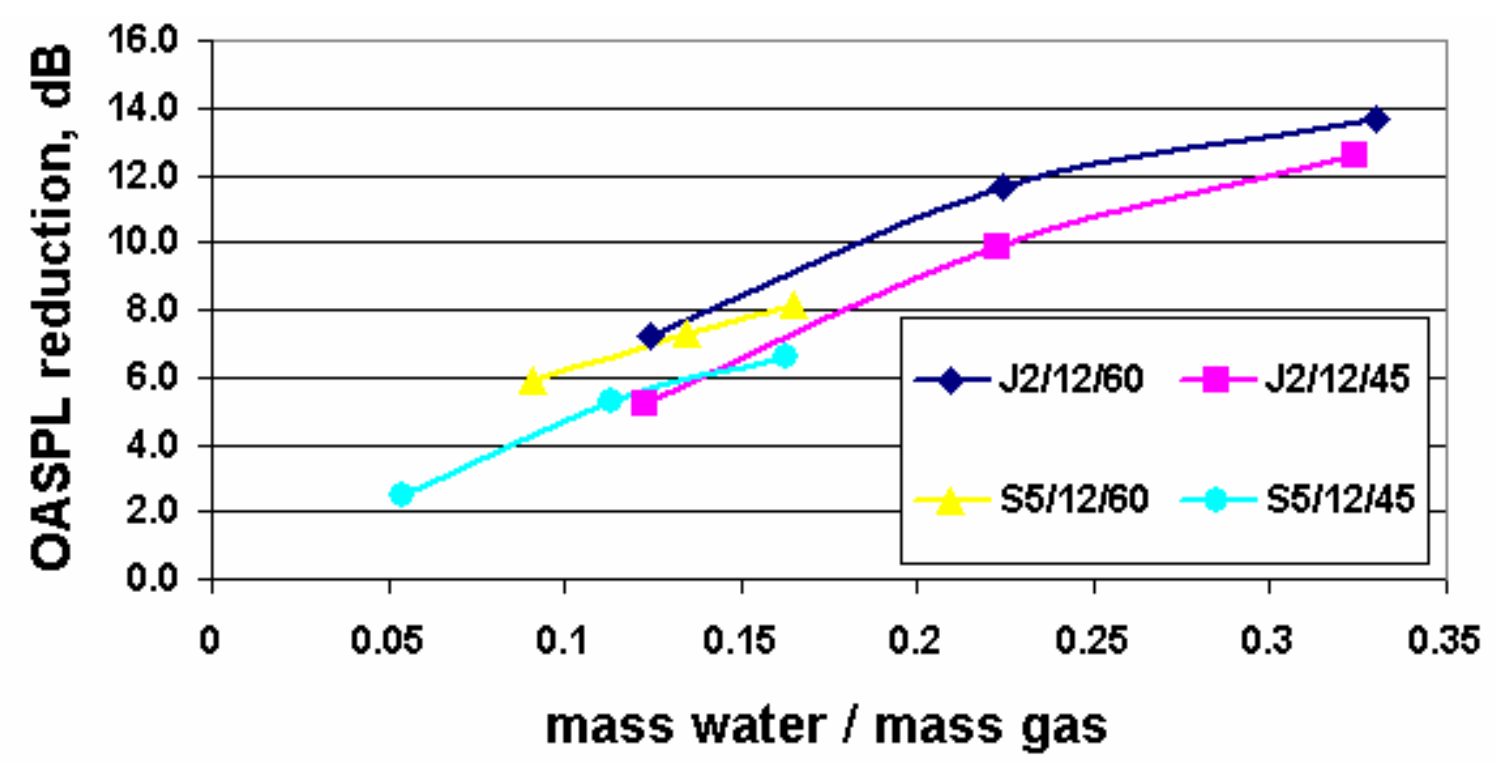

Figure 10 Maximum reductions in OASPL vs. mass flow ratio of cold over-expanded supersonic jet broadband shock noise for jet and spray injectors at $45^{\circ}$ and $60^{\circ}$ injection angles.



Figure 11 Maximum reductions in OASPL vs. mass flow ratio of cold over-expanded supersonic jet broadband shock noise at different axial injection locations, configuration $\mathrm{J} 2 / 12 / 60$. 


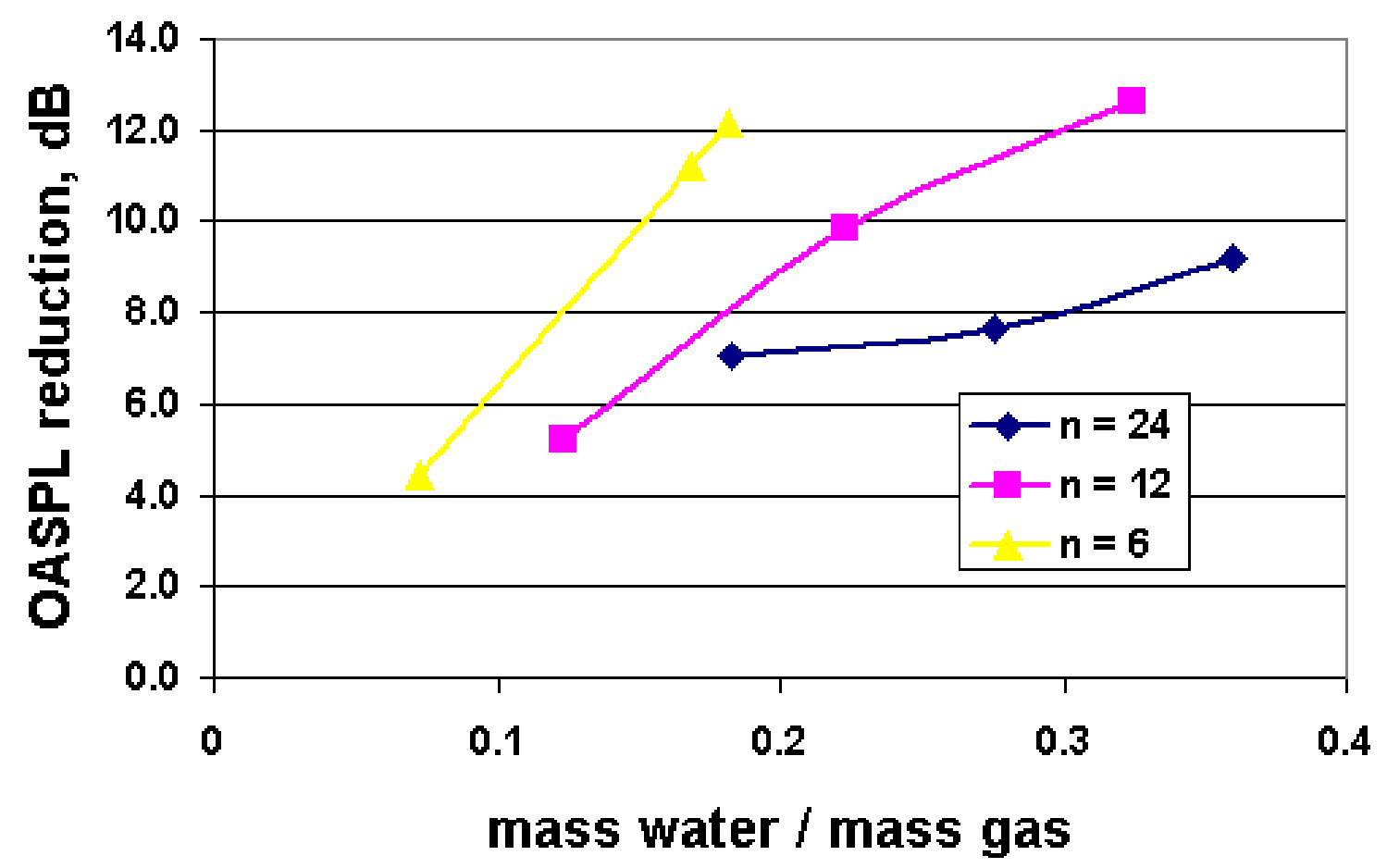

Figure 12 Maximum reductions in OASPL vs. mass flow ratio of cold over-expanded supersonic jet broadband shock noise for different numbers of injectors, injector $\mathrm{J} 2$ at $45^{\circ}$ injection angle.

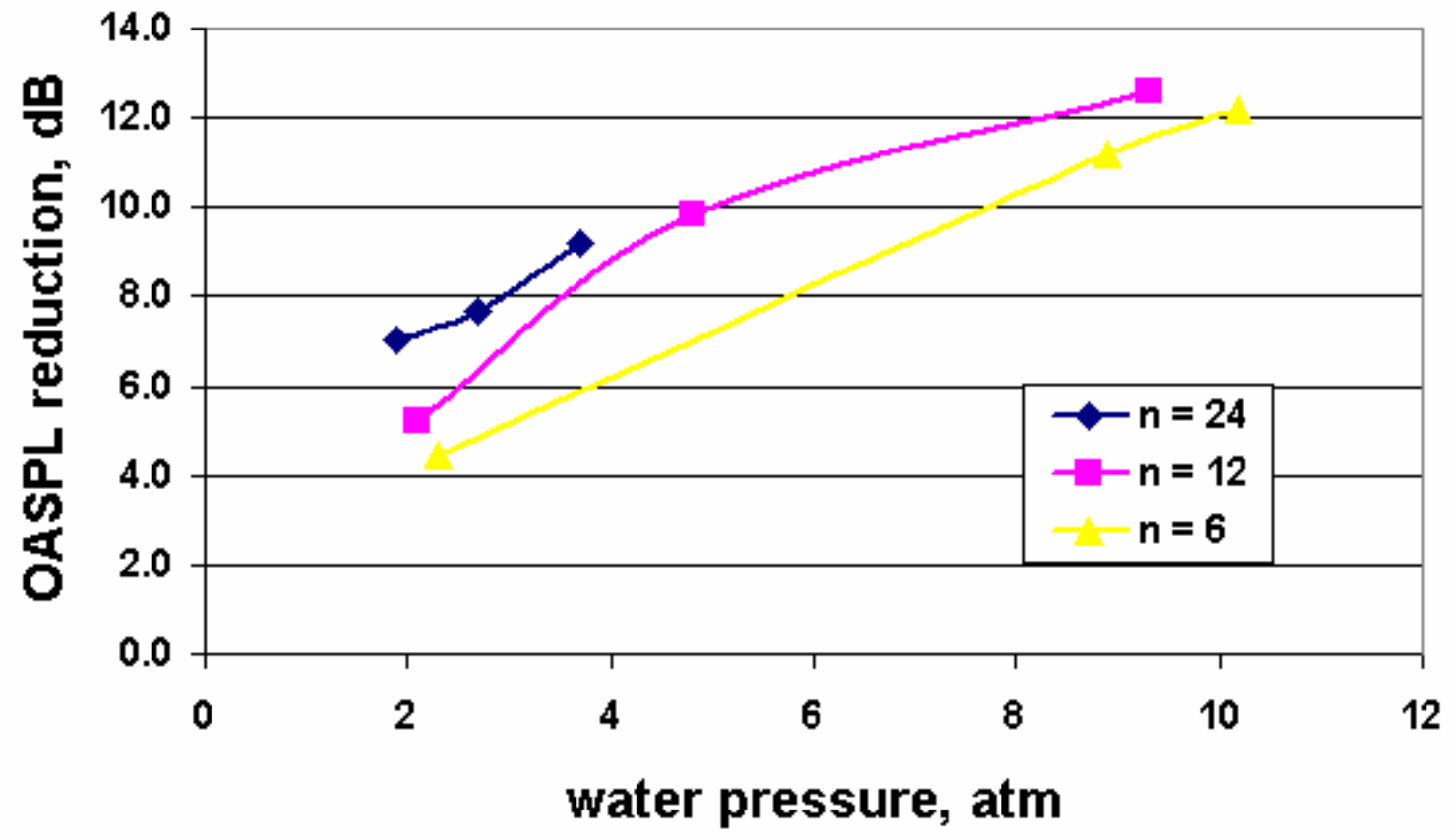

Figure 13 Maximum reductions in OASPL vs. water pressure of cold over-expanded supersonic jet broadband shock noise for different numbers of injectors, injector $\mathrm{J} 2$ at $45^{\circ}$ injection angle. 

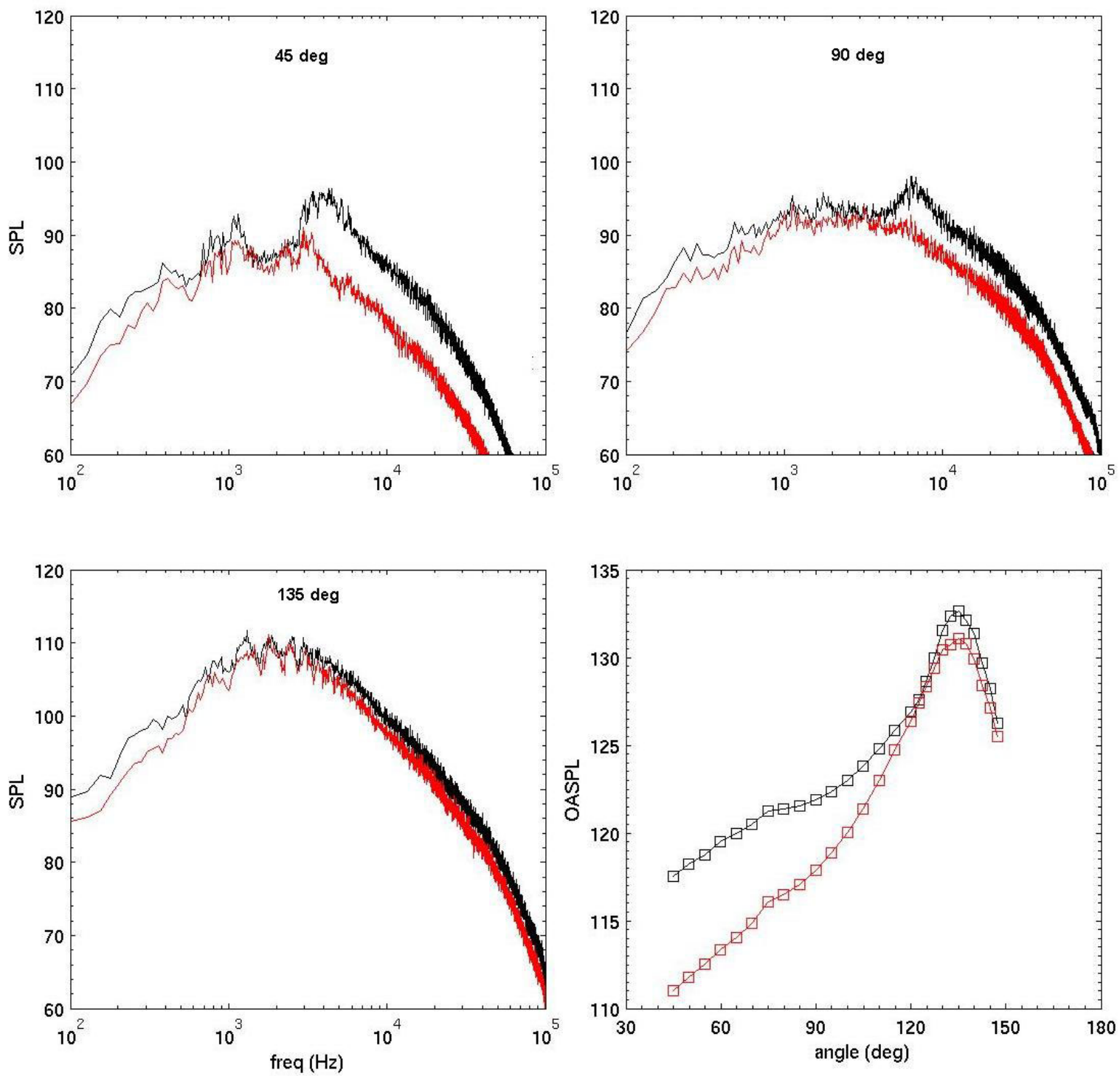

Figure 14 Spectra and directivity of hot over-expanded supersonic jet broadband shock noise, configuration $\mathrm{J} 2 / 12 / 45$. MFR $=0$ - black, MFR $=0.46$ - red. 

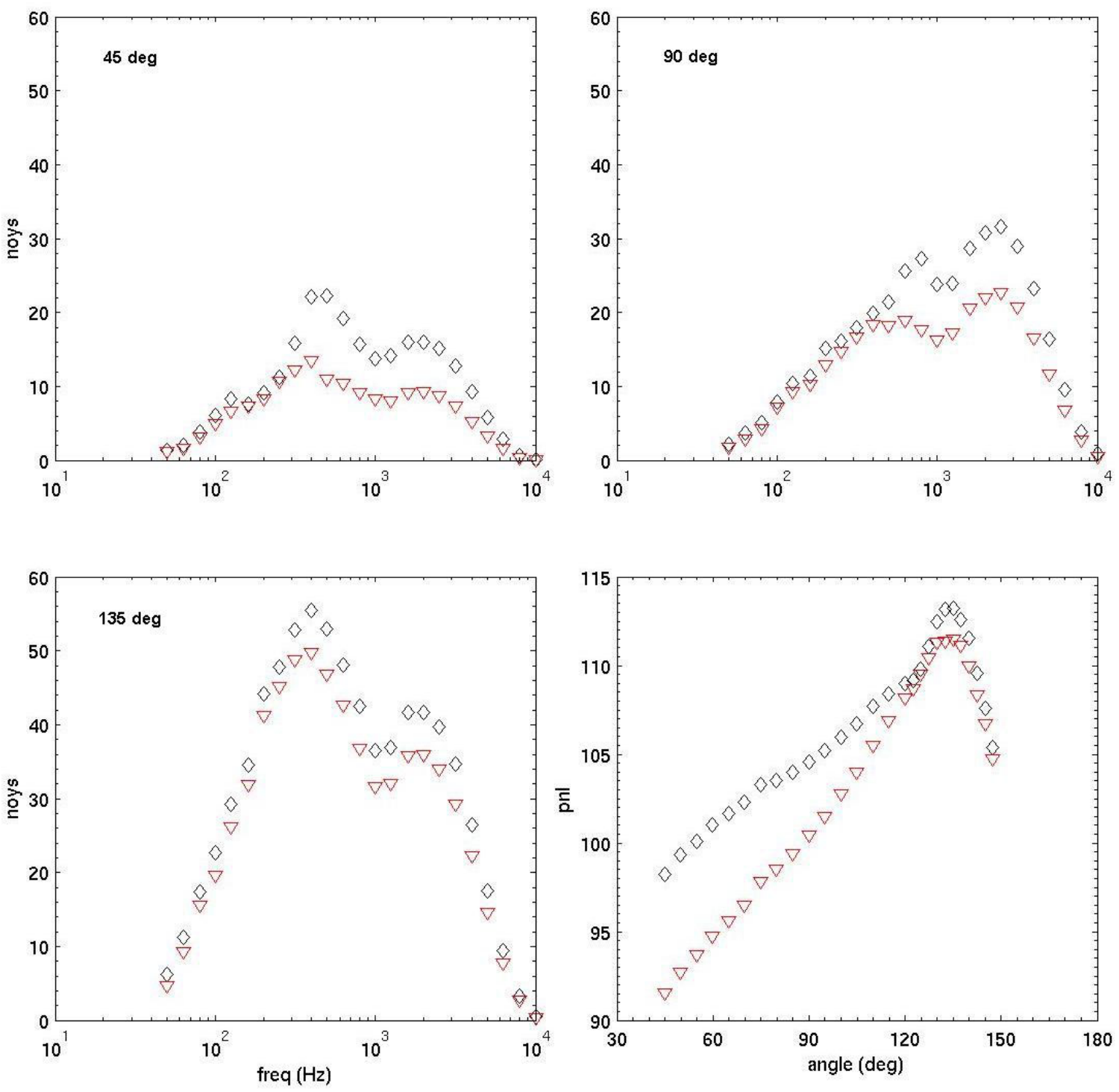

Figure 15 Full-scale noy spectra and PNL directivity of hot over-expanded supersonic jet broadband shock noise, configuration $\mathrm{J} 2 / 12 / 45$. MFR $=0-$ black, $M F R=0.46-$ red, $\triangle E P N L=1.3 \mathrm{~dB}$. 

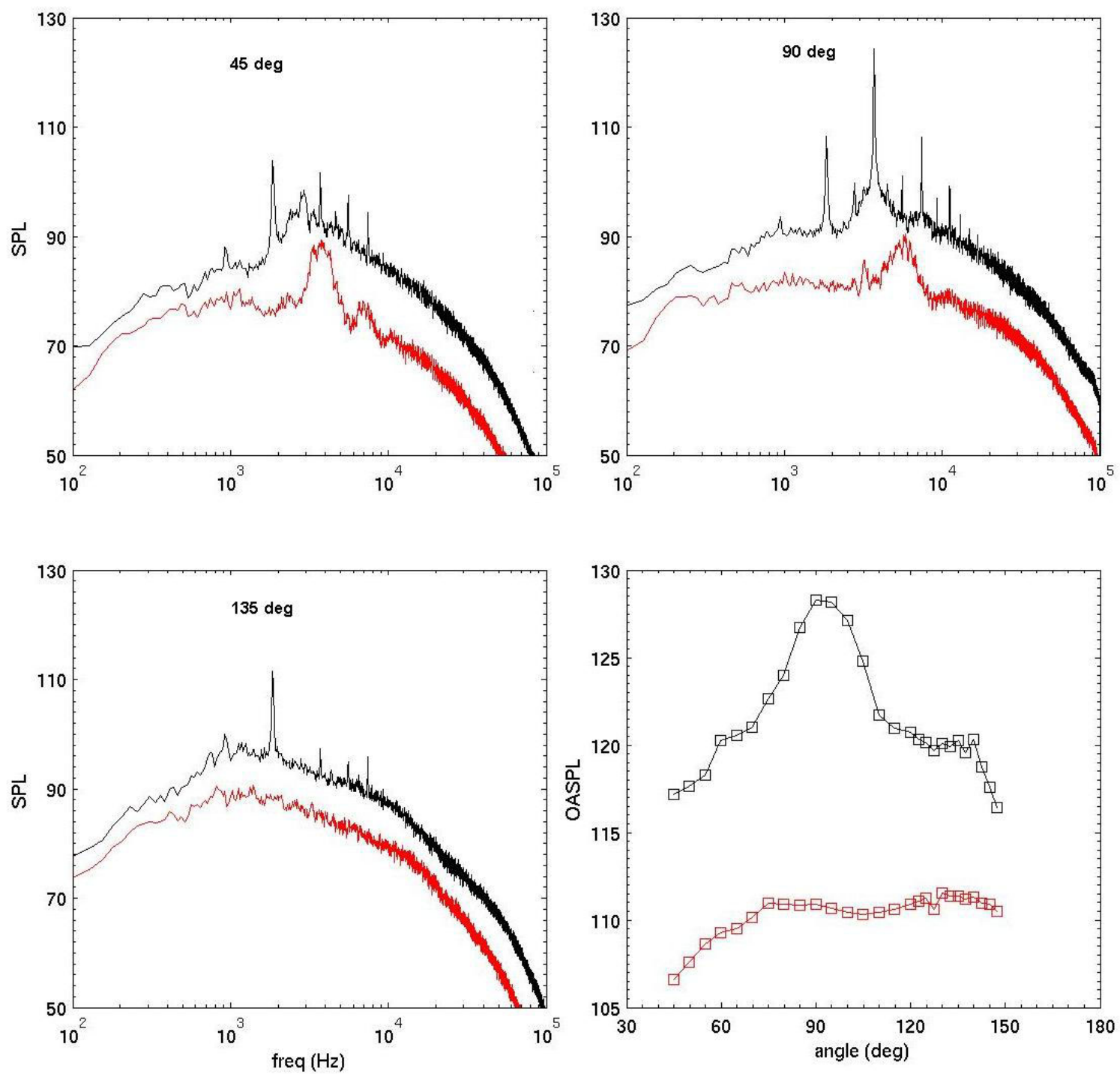

Figure 16 Spectra and directivity of cold under-expanded supersonic jet screech, configuration J2/12/60. MFR $=0$ - black, MFR $=0.28-$ red. 

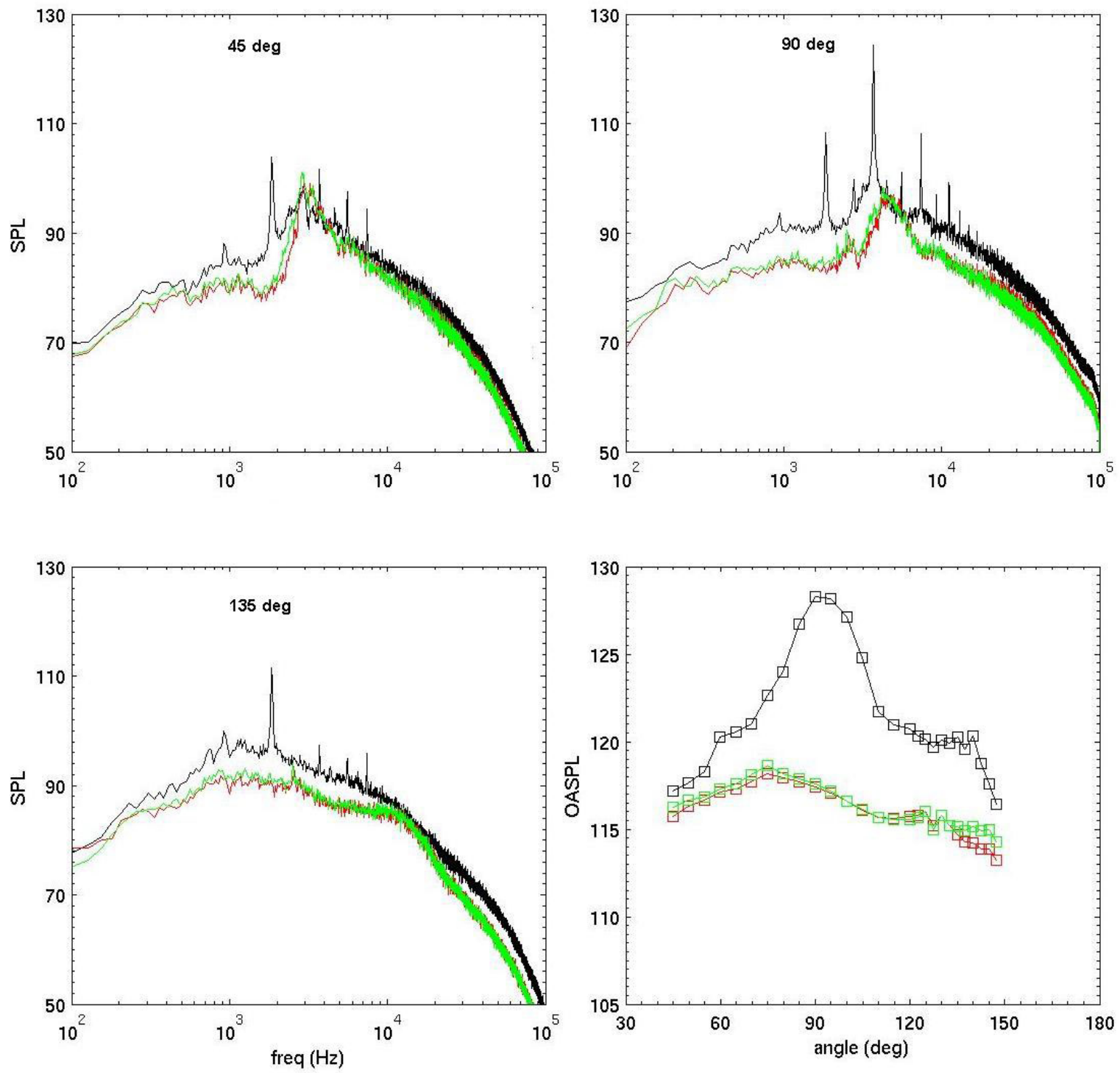

Figure 17 Spectra and directivity of cold under-expanded supersonic jet screech with 12 injectors at $60^{\circ}$ injection angle. $\mathrm{MFR}=\mathbf{0}$ - black, $\mathrm{MFR}=\mathbf{0 . 1 0}$, injector $\mathrm{J} 2$ - red, $M I F R=0.10$, injector $\mathrm{S} 5$ - green. 


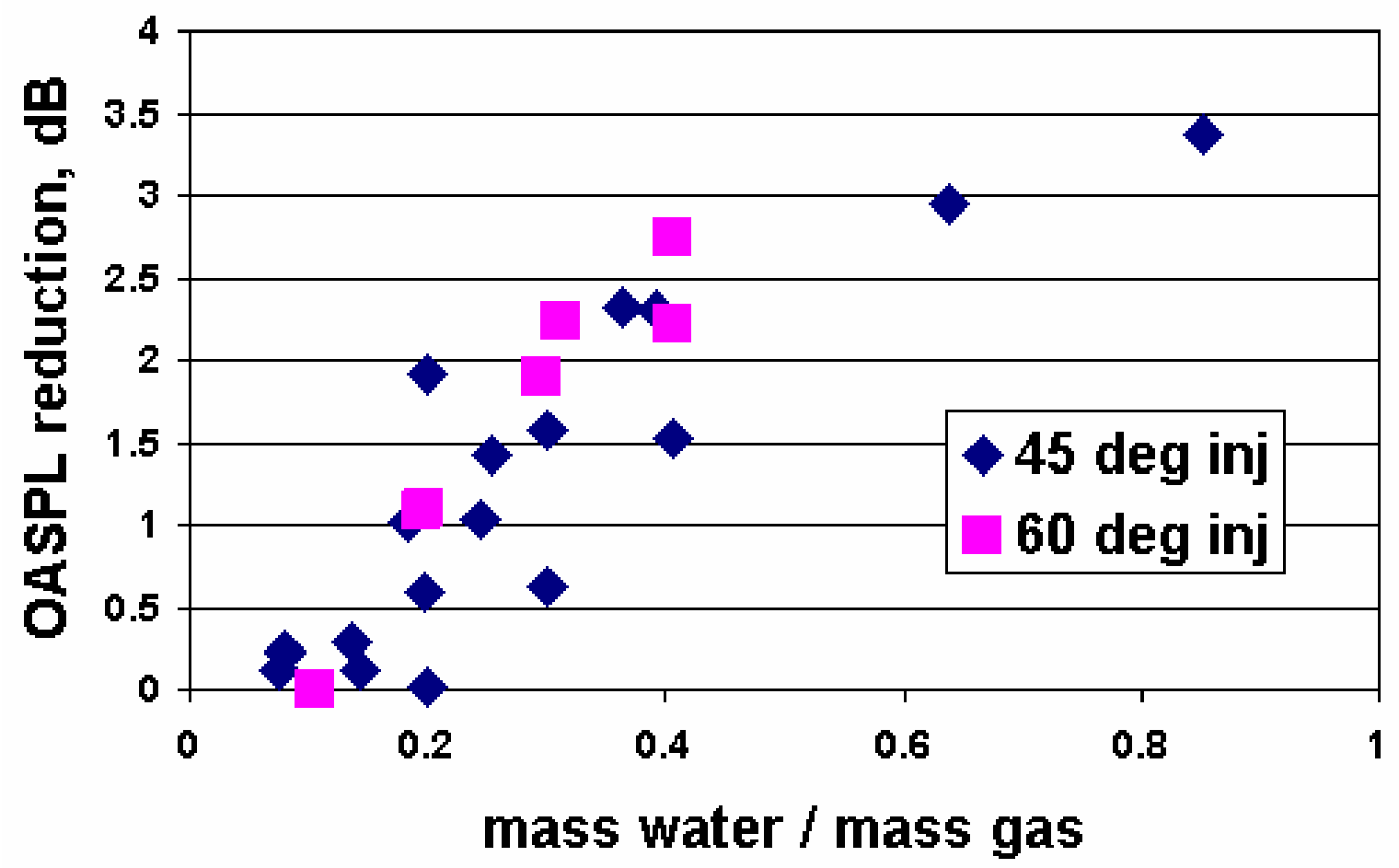

Figure 18 Maximum reductions in OASPL vs. mass flow ratio of hot supersonic jet mixing noise at $45^{\circ}$ and $60^{\circ}$ injection angles for various injector types $(\mathrm{J} 2, \mathrm{J3}, \mathrm{S5}$, and $\mathrm{S} 7)$ and quantity $(6,12$, and 24$)$. 

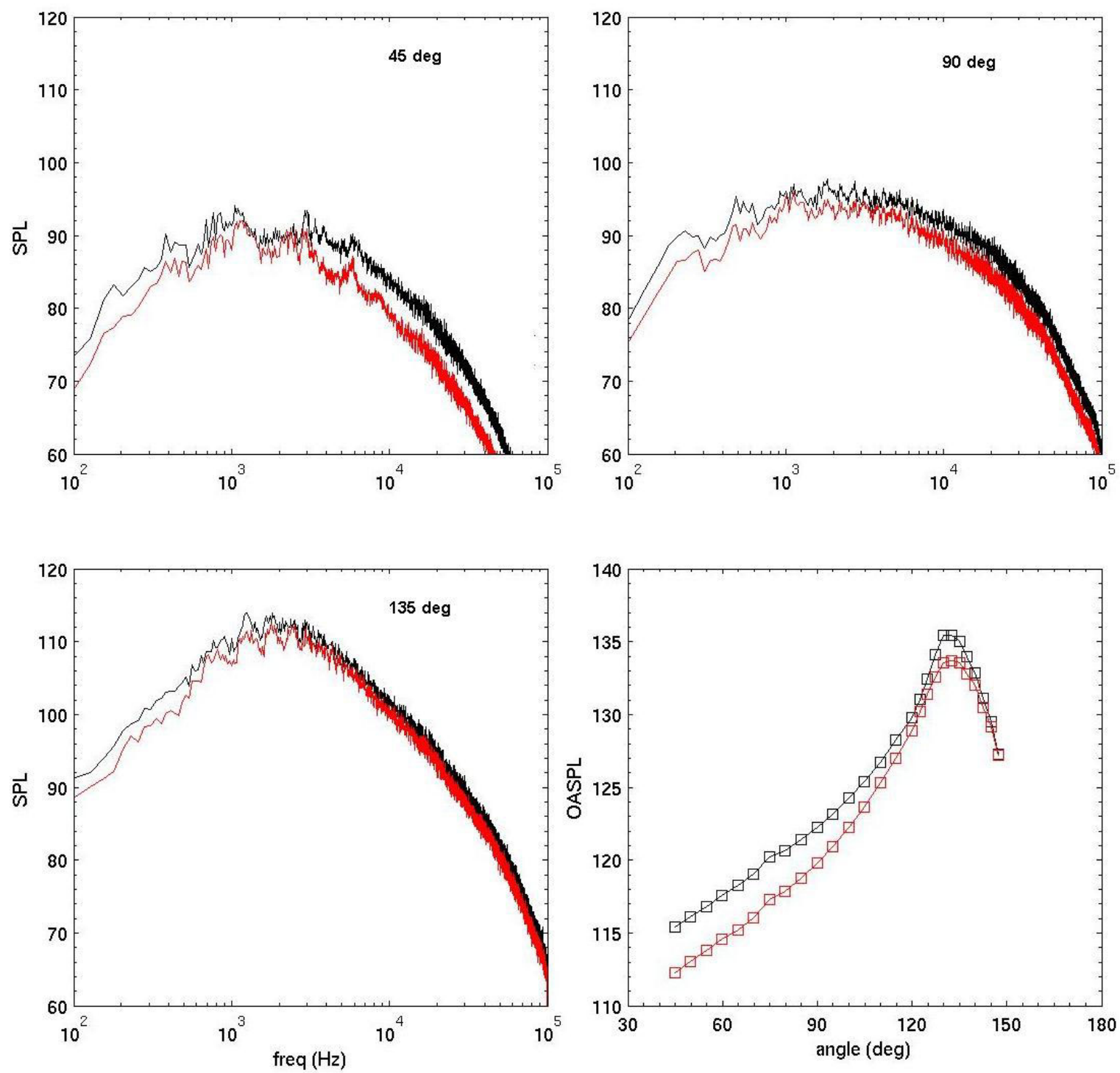

Figure 19 Spectra and directivity of hot supersonic jet mixing noise / Mach wave radiation, configuration $\mathrm{J3} / \mathbf{1 2} / \mathbf{4 5}$. MFR $=0$ - black, $M F R=0.85-$ red. 

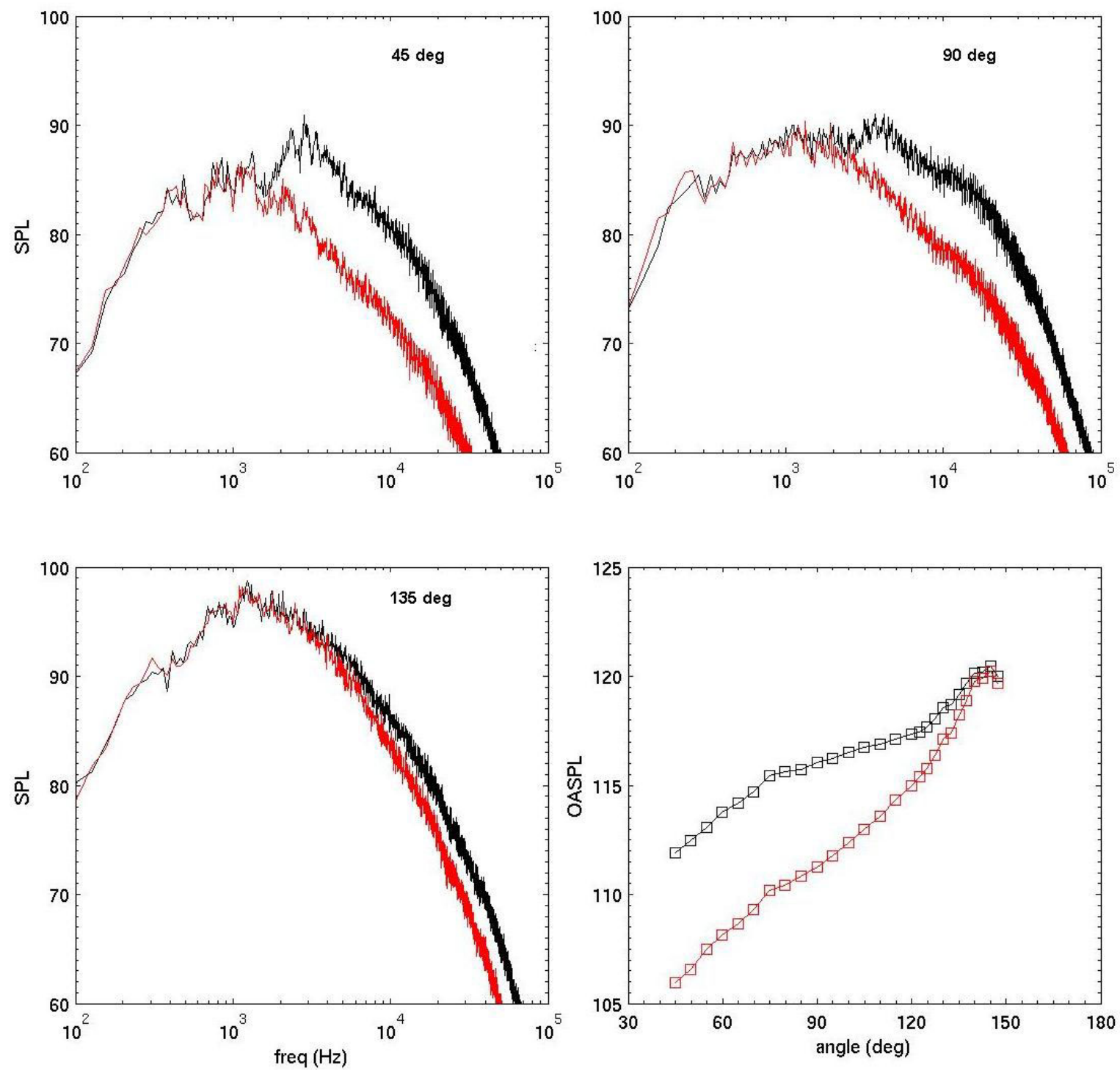

Figure 20 Spectra and directivity of cold supersonic jet mixing noise, configuration S5/24/60. MFR $=0$ - black, MFR $=0.19$ - red. 

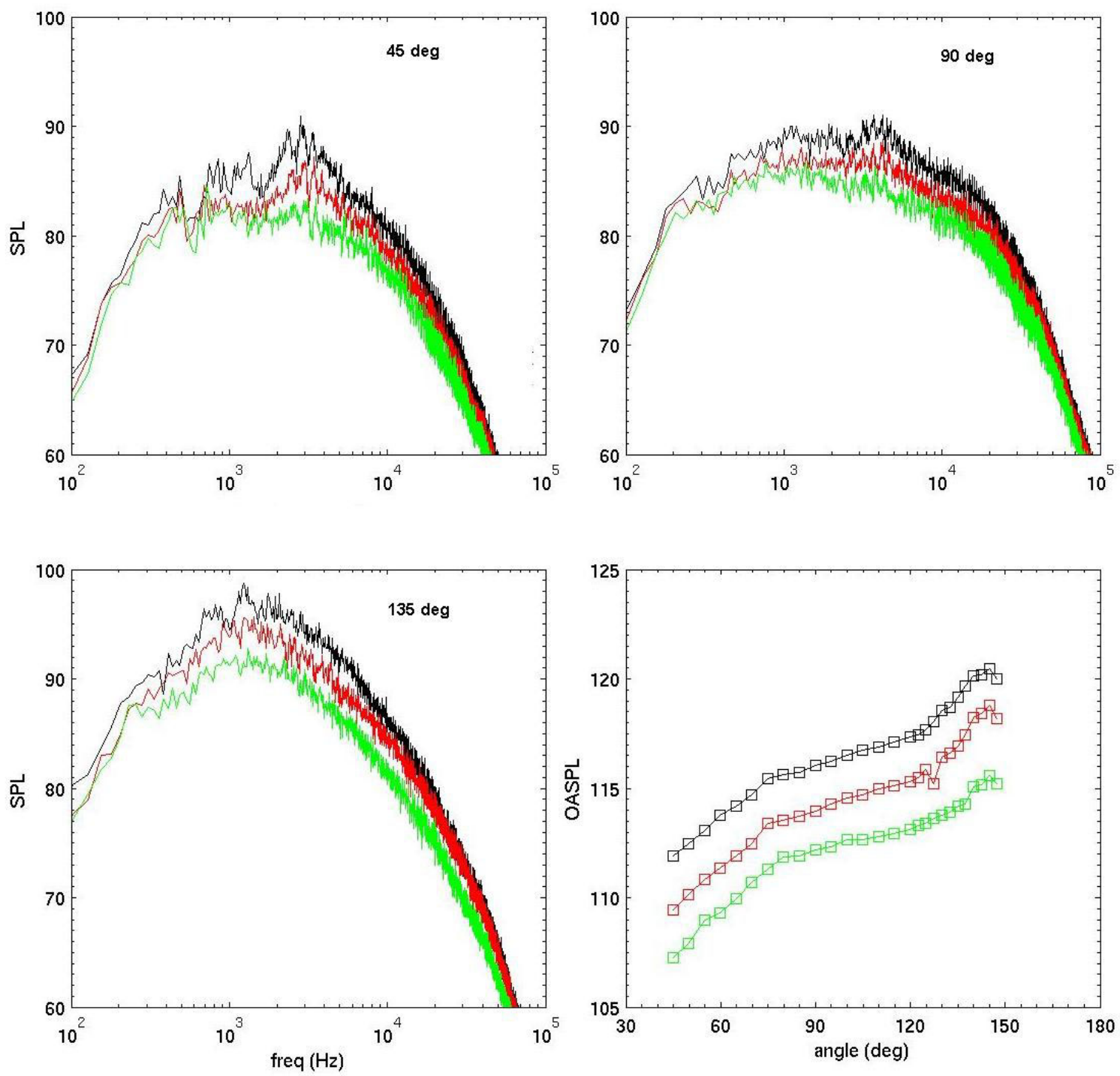

Figure 21 Spectra and directivity of cold supersonic jet mixing noise with no water injection. Water injection hardware installed, test section at $34^{\circ} \mathrm{F}$ - black (a), posttest with clean facility, test section at $51^{\circ} \mathrm{F}-$ red (b), pretest with clean facility, test section at $89^{\circ} \mathrm{F}$ - green (c). 